\title{
HOMO ACADEMICUS: CRISE IDENTITÁRIA E PRÁTICA CIENTÍFICA ${ }^{1}$
}

Dina Maria Martins Ferreira*

O conceito de intelectual foi inventado como um grito de zombaria, uma tentativa de ressuscitar as reivindicações insatisfeitas do passado.

BAUMAN $^{2}$

\section{RESUMO}

Este estudo visa argumentar sobre o construto identitário do homo academicus, ou seja, o intelectual que se estabelece no campo universitário compartilha habitus e atitude dóxica (Bourdieu, 2007; 2009; 2011). No que tange às etiquetas identificadoras, Bauman (2007) categoriza o intelectual pela prática científica, situada por relações históricas. Na convergência entre espaço, valores e performativos, constrói-se uma estrada da qual emerge a prática logocêntrica que se transforma em dogma a partir da permanência de práticas dóxicas do século das Luzes.

PalaVRas-ChaVe: identidade, logos, dogma, doxa.

\section{EMBaralHamento CATEGORIAL}

A primeira questão desse estudo é refletir sobre o que estamos chamando de homo academicus, porquanto são muitas as relações e correspondências na identificação do "homem acadêmico". Vários lugares identificadores podem ser levantados, tais como o pesquisador filiado a uma universidade, o docente titulado (doutor, pós-doutor, Ph.D etc.), o pensador ermitão famoso pelo saber filosófico etc. Mas, a mis-

\footnotetext{
* Professora Visitante, concursada, do Programa de Pós-Graduação em Linguística, do Centro de Humanidades, UECE. Pós-doutora em Linguística e Ciências Sociais pela Unicamp e Sorbonne V (2009-2010), pós-doutora pela Unicamp (2002-2003), doutora pela Universidade Federal do Rio de Janeiro (1995), Mestre em Análise do Discurso pela Pontifícia Universidade Católica do Rio de Janeiro (1988).

Email: dinaferreira@terra.com.br
} 
celânea designadora de identidades também se processa pela multiplicidade relacional entre sujeitos e seus contextos em que as identificações ocorrem, ou seja, ora no embate entre o muro acadêmico e o social do lá-fora, dentro de um único muro acadêmico e seus agentes, ora entre instituições acadêmicas diferentes. Nortear e sistematizar flancos fluidos é quase impossível pela própria acepção de iterabilidade (DERRIDA, 1999) dos sentidos, pois nunca se esgotam na repetição por traduzirem continuamente o novo.

Mesmo diante de tantas "etiquetas", direcionamos o nosso telescópio para a figura do intelectual como o acadêmico proprietário do logos instituído no campo universitário. E ainda assim, muitas imprecisões refletem a dificuldade de delimitar, se o é possível, o acadêmico, sua identidade e sua prática científica, pois está no próprio conceito de nomeação de identidade a problemática. Por mais que se tente "discursar" sobre o processo identitário do acadêmico, não posso abrir mão de, aqui, utilizar identificações. Se estou no estado de identificação, eu corto o processo performativo, caindo no precipício dos constativos (AusTIN, 1962). Mesmo que eu afirme que identidade é um construto - um processo contínuo de reivindicações e performativos -, preciso apontar identificando para defenestrar o processo ad continuum. Enfim, preciso do fetiche para desconstruí-lo (FERREIRA, 2009; 2010).

Diante dos jogos de linguagem que traduzem "formas de vida" identitárias (WITTGENSTEIN, 1989), quem/como seriam os acadêmicos, os intelectuais, os cientistas, os pensadores, os pesquisadores etc.? Quais os sentidos iteráveis de suas identidades, quais suas formas de vida? Se a linguagem é entendida como imersa em uma forma de vida cultural, como definiu Wittgenstein, em Investigações filosóficas (1989, § 23, p. 18), quando afirma que o "falar da linguagem é parte de uma atividade ou de uma forma de vida" e que "representar uma linguagem significa representar-se uma forma de vida" (§ 19, p. 15), como fronteirizar sentidos por categorizações constativas com o fim de nomear identidades?

A dificuldade de fronteirizar categorias identitárias se exemplifica no discurso mídiático, que demonstra como os jogos de linguagem "desorganizam" fronteiras designativas, porquanto, catalogar os espaços como em um atlas geográfico seria confortável e, mais ainda, designar seus habitantes. Nos fragmentos a seguir, podemos apontar os habitantes da intelligentia - intelectual, pensador, filósofos, tradutor, 
autor, membro, médico, sociólogo, pesquisador, scholars - se deslocando aleatoriamente de um lugar para outro - sociedade, academia de letras, universidade, torre de marfim, instituição, sala de aula: ${ }^{3}$

(1) Acadêmico Arnaldo Niskier lança seu $98^{\circ}$ livro

Intelectual recebe o apoio da família e de Gilberto Braga

[...] afirmou o membro da Academia Brasileira de Letras

(Revista Caras, 28 de agosto de 2010, p. 33);

(2) O complexo percurso de Edgar Morin.

Ponto algo. "Quando os intelectuais descem da torre de marfim e defendem ideias de valor social convertem-se em intelectuais", acredita Morin [...] Morin lança luzes sobre sua estrada e reitera a seus leitores a força da ética [...] da convicção pessoal na formação de um pensador irrepreensível[...] Quando os filósofos descem de sua torre de marfim [...] (jornal Folha de S. Paulo, 24 de julho de 2010, p. S6);

(3) Geraldo Cavalcanti toma posse na ABL.

Aos 81, diplomata, tradutor e autor pernambucano sucede José Mindlin na cadeira 29. [...] Diplomata, poeta, escritor e tradutor [...] "A academia é uma instituição tão especial que qualquer pessoa que se dedique, sobretudo, à vida literária não pode deixar de se sentir honrada a ver na academia a culminância do reconhecimento como intelectual e como escritor" (jornal Folha de S. Paulo, 19 de outubro de 2010, p. A14);

(4) Letra de médico. O médico Raul Cutait tomou posse na Academia Paulista de Letras, anteontem, na vaga que era [...] (jornal Folha de S. Paulo, 28 de agosto de 2010, Ilustrada, p. E2);

(5) ONG resgata acadêmicos perseguidos.

Scholars at Risk [Pesquisadores em Risco], nos EUA, oferece trabalho em universidades a intelectuais que fogem de regimes autoritários.

A iraniana [...] professora universitária no Estado de Massachusetts [...] Atualmente, com a participação de 230 universidades e instituições em quase 30 países, funciona como uma rede internacional de informação e articulação, que, com quase 500 professores e pesquisadores voluntários, levanta informações, fundos e negocia posições para os acadêmicos em perigo (jornal Folha de S. Paulo, 25 de setembro de 2010, Mundo, p. 6);

(6) Universidade do século 21.

No início do século passado, o renomado sociólogo alemão Max Weber observou que somente por acaso se poderia encontrar em um 
mesmo homem as vocações de cientista e professor. Apenas em situações fortuitas teríamos a felicidade de entrarmos em uma sala de aula e depararmos com o acadêmico igualmente "vocacionado para o ensino e para a pesquisa" (jornal Folha de S. Paulo, 6 de janeiro de 2010, p. A3);

(7) Pesquisador trabalha em laboratório de campus da USP Ribeirão Preto.

Hoje, os cientistas recebem dinheiro de fora, como da Fapesp, que em 2009 destinou R \$319 mi à Universidade (jornal Folha de $S$. Paulo, 20 de outubro de 2010, A23).

Como se pode observar, o acadêmico ora está na universidade ora na instituição Academia dos imortais, ora em laboratórios providos por recursos externos; ora acadêmico é escritor e poeta, ora é intelectual e pensador, ora é cientista, e assim por diante. Não há como prever, por exemplo, um gráfico explanador e catalogador que delimite o habitat identitário de cada sujeito. No entanto, deixa-se entrever, tanto pelo senso comum quanto pelas nomeações midiáticas, que o acadêmico está mais ligado à universidade e o intelectual e cientista não necessariamente; o que significaria que nem todo acadêmico é intelectual e cientista, e que nem todo intelectual e cientista é acadêmico, fora a tendência "positivista" de catalogar o sujeito cientista como pesquisador das ciências exatas, aquele que habita os laboratórios experimentais e comprobatórios, considerados os "verdadeiros" agentes da ciência "pura". Diante de tantas prerrogativas identitárias, talvez a única categoria que desse conta de um lugar amplo e fluido fosse o espaço do conhecimento, cujos habitantes se aliam pela categorização de homem do saber. No entanto, o lugar do sujeito da ciência e sua prática percorrem, muitas vezes, ruelas de ortodoxia, de tal forma que não sobra ninguém, pois

[...] com frequência, as ciências funcionam como verdadeiras seitas, impedindo que os adeptos pensem livremente. A ciência também dos dogmas [...] Os que se atrevem a questionar os dogmas são sumariamente excomungados ou, no caso da ciência, tachadas de "pseudocientistas", "charlatões" etc. (Rajagopalan, 2003, p. 49)

Como diz Bourdieu ([1984]2011, p. 36-37), as categorizações, como uma "concorrência simbólica", recorrem 
a etiquetas classificatórias que designam ou referenciam grupos bem como grupos de propriedades sincreticamente apreendidos [...], por exemplo, os critérios pertinentes para definir o poder universitário ou a hierarquia dos prestígios [...]. Na verdade, basta pôr à prova esta técnica para ver que ela reproduz a própria lógica do jogo que se presume ela arbitre: os diferentes "juízes" - e o mesmo "juiz" em diferentes momentos - aplicam critérios diferentes, e até mesmo incompatíveis, reproduzindo assim, mas somente de maneira imperfeita porque em situação artificial, a lógica dos julgamentos classificatórios que os agentes produzem na existência ordinária.

\subsection{Algumas tipologias}

Não seria esse emaranhado de etiquetas nada mais do que uma auto-identificação que o próprio acadêmico se dá? Bourdieu ([1984]2011), ele mesmo, se coloca em posição difícil de "definir" o que seria acadêmico e intelectual, justificando que possíveis tipologias não são verdadeiramente concretas. Mas, se atentarmos para tal problemática de uma "posição difícil de definir", o autor se utiliza de classificações identitárias, alocadas no campo universitário. E nesse campo universitário várias funções-atuação se "combinam, na desordem, diferentes princípios de oposição, misturando critérios tão heteróclitos como a idade, a relação com o poder político ou com a ciência etc." (Bourdieu, 2011, p. 34). Primeiramente, abordamos as tipologias de Gouldner (1957, apud BOURDIEU [1984]2011, p. 34), tendo assim:

(a) o cientista local ou paroquial, ou seja, aqueles fortemente dedicados à instituição, verdadeiros burocratas, "seguranças/vigilantes" e os mais antigos da casa;

(b) o cientista cosmopolita, ou seja, os outsiders (os de-fora), os construtores do império.

Essas classificações (cf. Gouldner, 1957) se distinguem entre si em função do olhar em relação à instituição, tendo em vista o investimento nas competências profissionais e na orientação em direção ao seu interior e exterior.

Bourdieu se preocupa em apresentar também as tipologias de Clark (1963) e de Gustad (1966), que aqui reproduzimos com o objetivo de demonstrar a complexidade classificatória, ou melhor, as 
"identificações das identidades" do habitante titulado de universidades. Clark (1963) classifica a partir de diferenciações, que Bourdieu chama de "culturais", e que eu traduziria por diferenças toponímicas, pois estariam vinculadas aos lugares de atuação: a) sala de aula: o professor dedicado a seus alunos; b) laboratório: o pesquisador-scholar totalmente engajado ao seu laboratório; c) anexo: o tipo de monitor agregado, com a função de transmitir competências técnicas; e d) avião: o consultor, que passa mais tempo em avião do que no campus universitário.

Já Gustad (1966) classifica também pelo caráter funcional, mas, independente de estar se referindo ao espaço universitário, generaliza em sua classificação, pois reproduz uma estrutura aplicável a qualquer "empresa", seja privada ou pública. Assim temos: a) o scholar, um cidadão, pensador livre, para além dos muros universitários; b) o auditor de currículos; c) o empreendedor individual; d) o consultor; e) o administrador; e f) o cosmopolita.

Se pudéssemos reduzir as performatividades do sujeito acadêmico-universitário a essas classificações apresentadas, seria muito mais simples identificá-lo e carimbá-lo. No entanto, ficamos com todas as misturas tipológicas, talvez mais direcionadas ao que Gouldner (1957) propõe, pois seus dois conjuntos, o acadêmico paroquial e o cosmopolita, permitem-nos oscilar nas multiplicidades e particularidades diferenciais de atitudes, comportamentos, sociabilidades (entre pares e não pares no interior do espaço universitário) do homo academicus.

\section{NA PRÁTICA CIENTÍFICA: LEGISLADOR E INTÉRPRETE}

Uma explanação objetiva - recurso estratégico de organizar um fazer teórico - desse emaranhado designativo seria a proposta de Bauman (2007), que avalia as identidades acadêmicas, levando em conta a forma como a práxis científica se realiza, relacionando-a a determinado momento histórico e ao objeto de pesquisa. E nesse jogo entre o momento histórico e a escolha do objeto de pesquisa, tanto podemos dizer que um intelectual tem uma prática científica medieval vivendo em pleno século XXI, como afirmar que um pensador que viveu no século XVIII já apresentava uma práxis moderna, senão pós-moderna, de cientificidade. Bauman reforça com contundência que a identidade 
do acadêmico se ancora muito mais em sua "forma" de produzir conhecimento, sem negar sua referência histórica, do que o contrário. $\mathrm{O}$ autor, em sua argumentação, apresenta uma dupla classificação para o intelectual, ou seja, o moderno e o pós-moderno:

A oposição entre modernidade ou pós-modernidade foi aqui empregada a serviço da teorização dos três últimos séculos da história da Europa ocidental (ou da história dominada pelo Europa ocidental) do ponto de vista da práxis intelectual. É esta prática que pode ser moderna ou pós-moderna: a dominação de um ou do outro dos dois modos (sem que não deixe ela de sofrer exceção) distingue a modernidade e a pós-modernidade enquanto períodos da história intelectual. (BAUMAN, 2007, p. 6-7)

E por essas categorizações Bauman faz a distinção entre o intelectual legislador e o intelectual intérprete - legislador estaria para o moderno e o intérprete para o pós-moderno. Essas classificações não essencializam os momentos históricos, mas visam a uma "comunicação sem distorções" (HABERMAS, 2001) em que posições "tradicionais", tendo por base o século das Luzes, caminham em direção à contemporaneidade, sem deixar de fazer alusão a momentos anteriores - um caminho para entender o que seja o "ser intelectual".

Legislar estaria para ditar leis, e o legislador seria aquele que impõe centros fixos de leis que devem ser obedecidas para se ter o status de intelectual. Nessa imposição, não podemos deixar de lembrar que a opção entre legislar e interpretar está ligada à crença do acadêmico estar construindo pelo menos a sua Verdade, quando seria melhor que construísse sua verdade (com letra minúscula), pois assim estaria admitindo que existem outras tão importantes quanto a dele e tão necessárias para o crescimento científico quanto para o de um olhar múltiplo.

Já o "intérprete", pós-moderno, não visa a eliminar a "tradição" do legislar; sua função é questionar a perspectiva essencialista da tradição como geradora de Verdade universalizante, até porque, como já anotado anteriormente, precisa-se do fetiche para desconstruí-lo: "a estratégia pós-moderna não implica a eliminação da estratégia moderna; ao contrário, ela não pode ser concebida sem a continuação desta última"s (BAUMAN, 2007, p. 10). Sua função, enfim, é "traduzir", ou seja, 
traduzir as ideias nascidas no interior de uma tradição dada a fim de que elas possam ser cumpridas em um sistema de conhecimento baseado sobre uma outra tradição. Não procura achar o melhor possível de uma ordem social, mas de facilitar a comunicação entre as partes autônomas (e soberanas). (BAUMAN, 2007, p. 10)

Se o examinador da intelectualidade é um intelectual com visão moderna (tradição iluminista), ele diria que não haveria intelectual pós-moderno, e que seus discursos se restringem a ensaios caracterizados pelas impressões da subjetividade; para esse tipo de intelectual, só vale a lei do modelo, aquele que comanda. Mas, se o examinador for um intelectual de visão pós-moderna, este abarcará a multiplicidade, sem julgamentos de decretos de que só pode haver ciência se esta estiver presa a modelos a priori, em busca de traduzir o porquê das relações entre soberanias específicas.

Por tais prerrogativas, a legitimidade da ciência balançaria entre dois tipos de práxis: a moderna, com o sujeito "legislador"; e a pós-moderna, com o sujeito "intérprete". Enquanto a moderna visa à soberania do comando, a pós-moderna se esteia na interpretação desse comando. O legislador dá a suas ideias um caráter de autoridade que permite arbitrar controvérsias, selecionar e validar, porquanto o poder de arbitrar lhe permite aventar ter um conhecimento superior em relação ao resto da sociedade, com um acesso privilegiado à Verdade e à ordem social (cf. BAUMAN, 2007, p. 10), em prol da preservação da tradição intelectual.

\section{LOGOCÊNTRICO DOGMA E DOXA}

\subsection{Do logocentrismo ao dogma}

Para entender o que chamamos de dogma logocêntrico, um situatedness (histórico, político e psicológico) se faz válido. Percorremos o fazer do logocentrismo por categorias: primeiro, o poder do saber e segundo o medo das contingências (BAUMAN, 2007).

$\mathrm{Na}$ seara do poder, por exemplo, o clérigo em séculos anteriores era considerado intelectual - ser divino -, não só pela formação cultural que recebiam, mas também pela posição em relação aos homens 
dos corredores da vida. Eles viviam em espaços isolados - abadias e conventos - ainda não chamados de Academia, mas que não deixavam de ter semelhanças com os Jardins de Akademos de Platão (FerreirA, 2009; 2010), e dedicados aos estudos filosóficos e teológicos - um saber que se unia ao divino. Em contrapartida, os homens comuns eram responsáveis pelas ações, no sentido de realização rotineira do dia a dia. Tal fronteira divisória, entre saber-poder e vida comum, nos leva ao momento contemporâneo em que para ser intelectual - o proprietário de um logos divinatório - temos de nos separar do mundo comum.

Mas a grande "sacada" de Bauman (2007), a meu ver, foi aliar o saber-ermitão, que leva ao poder, ao medo e à insegurança humana. $\mathrm{O}$ autor, tomando como base o estudo de sociedade primitiva, utilizando a perspectiva de Radin, ${ }^{7}$ parte da ideia de que o ser homem tem como uma de suas facetas o medo, e como tal, estaria sempre em busca da segurança das verdades, como forma de aliviar suas inseguranças. Caberia, então, a um grupo privilegiado, ser o condutor da Verdade, com o poder de mantê-la e de exercitá-la. Se há pensadores, intelectuais, que adotam a função postural de veicular a Verdade (com letra maiúscula), tal como os clérigos, por que deveria esse grupo de homens abrir mão do poder de condução da Verdade Absoluta? Como condutores e proprietários da Verdade, não só dariam segurança ao homem comum, da ação repetitiva, como também a si próprios; a si próprios, tanto pelo fato de não se considerarem mais homens comuns e "frágeis", quanto pela manutenção da pretensa estabilidade que os "salva" do ordinário. E diante de tais prerrogativas - o medo abatido pela segurança -, podemos acrescentar à segurança do poder da(s) Verdade(s) o prazer de exercitar o poder. Se ao poder se junta o prazer, que esconde o medo, por que abrir mão da prática do poder? Talvez exista aí um vislumbre, mesmo que pequeno, de como o século das Luzes (talvez o século do Prazer) continua ainda entre os acadêmicos.

Medo e poder fazem uma "dobradinha" bastante eficaz na prática político-social dos clérigos, intelectuais e/ou acadêmicos - detentores do saber-poder e condutores da(s) Verdade(s) cuja linguagem, por exemplo, decreta o que seja "civilização", denomina o que sejam pensadores "pré-socráticos" bem depois da existência de Sócrates, e assim por diante. Daí as designações "intelectual" e "acadêmico" exercerem 
uma força centralizadora na manutenção dos olimpos e das "abadias" universitárias.

Nesse poder do saber, instaura-se a prática logocêntrica. E imediatamente podemos retornar aos Jardins de Akademo de Platão e ao

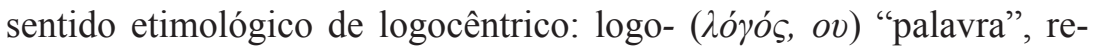
velação divina, razão e inteligência" (Isidro Pereira, 1976, p. 350); e -centr(o) ( $\chi \dot{\varepsilon} v \tau \rho o v, o v)$, "ponto central de um circunferência, aguilhão" (p. 317). Tais forças centralizadoras se tornam, muitas vezes, tão peremptórias, vide os sentidos gregos - razão no/do Verbo divino que aferroa no âmago -, que chegam à "altura" de um dogma, que, em sua natureza de crença de uma verdade inquestionável, chega ao ponto de se naturalizar. Mesmo que atualmente o imperialismo da mente tenha se subdividido em áreas específicas, ${ }^{8}$ os especialistas foram "destinados a criar seu próprio referente, provocando questões, mobilizando devoções, suscitando autodefinições [...] no centro de uma autoridade coletiva política, moral e estética, exercida pelos homens do saber (BAUMAN, 2007, p. 6) (itálicos acrescidos). ${ }^{9}$

Quando alio o sentido de dogma ao exercício logocêntrico, indico a presença valorativa do dogma como um efeito não só da durabilidade do poder, mas também do exercício cada vez mais ortodoxo para sua manutenção, haja vista a "devoção" que provoca a seus seguidores em contínua "autodefinição" de salvadores da legitimidade científica.

\subsection{Do dogma à(com) doxa}

A essa altura de minha argumentação, vejo a própria linguagem acadêmica que utilizo como fetiche, a partir do qual me permito desconstruí-lo. Ao mesmo tempo que legislo, tento traduzir. Ciente e consciente, vou a Caldas Aulete (1964, p. 1272) e registro o sentido de dogma como "um ponto de doutrina religiosa ou filosófica apresentado como fundamento certo e indiscutivel de uma crença ou sistema". Mas não me satisfaço, e vou à etimologia de dogma, com o sentido de "decisão e decreto" (NASCENTES, 1932, p. 254), que por sua vez me leva à sua nascente grega, $\delta o ́ \gamma \mu \alpha, \alpha \tau o \varsigma$, "opinião, decisão, decreto, sentença"

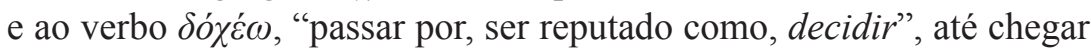

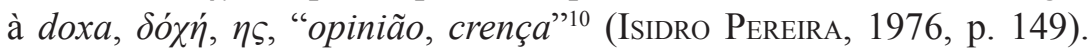


Todo esse percurso conjumina sentidos no campo semântico da crença e opinião, ou seja, uma opinião que adquire o status da crença.

Até então os sentidos levantados parecem estar no mundo individual de quem opina descompromissadamente. Mas a questão da torre de marfim divinatória da identidade acadêmica é mais complexa do que imaginamos, porquanto se trata de uma "crença" legitimada pelo "poder simbólico" (Bourdieu, [2001]2007; Chevallier \& Chauviré, 2010). Apesar da proposta bourdieusiana negar que o que chama de doxa se refere à simples opinião, não podemos deixar de entrever uma crença arraigada, a tal ponto de nem mais merecer questionamentos. Não seria o poder simbólico uma forma de dominação dogmática? Não é impune a escolha do subtítulo - do dogma à doxa em que embuti o dogma com a doxa -, justamente com o intuito de não separar doxa de dogma, e inclusive dar à noção de dogma uma legitimidade sociopolítica.

E Bourdieu ([1984]2011; [1980]2009; [2001]2007) junto a Chevallier \& Chauviré (2010) nos proveem de argumentos. Ou seja, estamos em determinado "campo", ou melhor, em um mundo social que se decompõe em grande multiplicidade de microcosmos, no caso o microcosmo universitário, que possui seus próprios jogos e empreendimentos, objetos e interesses específicos, um espaço que estabelece suas próprias regras, escapando, muitas vezes, de influências heteronímicas de outros campos. A noção de "campo" funciona junto com a de habitus, "estruturas estruturantes", um produtor de ações, produzidas pelos condicionamentos históricos e sociais:

Os condicionamentos associados a uma classe particular de condições de existência produzem habitus, sistemas de disposições duráveis e transponíveis, estruturas estruturadas predispostas a funcionar como estruturas estruturantes, ou seja, como princípios geradores e organizadores de práticas e de representações que podem ser objetivamente adaptadas ao seu objetivo sem supor a intenção consciente de fins e o domínio expresso das operações necessárias para alcançá-los, objetivamente "reguladas" e "regulares" sem em nada ser o produto da obediência a algumas regras e, sendo tudo isso, coletivamente orquestradas sem ser o produto da ação organizadora de um maestro. (Bourdieu, 2009, p. 87) 
Novamente volto a me preocupar com a noção de universalismo ou de determinismo que possa estar se formando na argumentação, já que estamos caminhando do logocentrismo-dogma à doxa. Mas, pelo contrário, o fetiche me obriga a identificar, e identificar é apontar para um ponto, só que esse ponto não é um centro universalizador, eu diria que está se mostrando como uma força de centrípeta e não que essa força tenha de acontecer e reagir obrigatoriamente de determinada forma, como se o habitus e o campo, quando determinados, funcionassem como um destino fatal (cf. BoURDIEU \& WACQUANT, 1992).

Quando enxergo o dogma na prática logocêntrica, vejo uma tendência praticada por grupos acadêmicos que não admitem observar para além de sua "mercadoria" de pesquisa à qual atribuem o sentido de existência de um dogma - Verdade Absoluta. É por essa circunstância dogmática que me dirijo à doxa bourdieusiana, que não está para uma maneira de pensar ou de julgar, mas sim para uma "atitude dóxica", ou seja, aderência a "um conjunto de crenças, associadas à ordem das coisas próprias de um dado universo [campo universitário], que se impõem de maneira pré-reflexiva, logo indiscutíveis, como evidentes e inevitáveis" (Chevallier \& Chauviré, 2010, p. 56). ${ }^{11}$ Doxa é constitutiva da noção de pertença a um campo, cujos pressupostos para aí serem incluídos constituem a atitude dóxica - pressupostos avaliativos e cognitivos que por sua vez formam a doxa. A inclusão de outros acadêmicos, no caso os iniciantes de concursos, por exemplo, depende, muitas vezes, do pertencimento às atitudes dóxicas desse campo.

Eu me pergunto: nessa atitude dóxica acadêmica, não estariam as atitudes divinas e as maneiras de consagrá-las para a constituição do "poder simbólico"? Trata-se de um poder que se faz simbólico, pois pressupõe uma obediência à força da dominação, ou seja, "o poder simbólico não designa uma forma particular de dominação, mas é a força que possui toda a dominação, na medida de se fazer reconhecida e de obter reconhecimento dentro de sua verdade de poder, de uma violência arbitrária" 12 (CHEVALLIER \& CHAUviré, 2010, p. 117). As famosas inclusões de novos acadêmicos no campo universitário, como por exemplo, editais para concursos, não conteriam exclusão providas pela força arbitrária do poder simbólico?

E nesse sentido podemos entender o caminho, bem contíguo, que se estabelece entre as práticas do logocentrismo que se perfaz de dog- 
mas, performatizadas por atitudes dóxicas do habitus no campo universitário.

\section{HоMO ACADEMICUS}

Na realidade, não podemos esquecer que as forças do poder/saber estão situadas em seus momentos históricos, com suas lutas políticas. Bauman (2007) deixa muito claro que, ao fazer a diferença entre modernidade e pós-modernidade, não está qualificando momentos culturais, mas sim a prática científica, ora em que o modelo dita as normas, ora em outras fora das regras modelares. Para esse autor, "a visão moderna é tipicamente aquela de uma totalidade relativamente ordenada: a presença de um motivo de distribuição de probabilidades permite uma forma de explicação dos eventos que [...] se constitui de instrumento de predição e até de uma matriz"13 (BAUMAN, 2007, p. 8) (itálicos acrescidos). Em tais circunstâncias, a justeza da matriz corresponderia à justeza do conhecimento que revoga por sua legitimidade. Já a visão pós-moderna do mundo é tipicamente aquela de um número ilimitado de modelos, gerados por um conjunto de práticas relativamente autônomas, em que "a ordem não precede as práticas e não pode inclusive medir sua validade" (BAUMAN, 2007, p. 9). ${ }^{14}$

Toda essa discussão sobre o construto identitário do homo academicus nos mostra atitudes dóxicas, que nada mais são que práticas políticas das/nas práticas científicas -, mesmo que dependentes de disposições estruturadas. As vozes a seguir, diante do habitus do campo acadêmico, ora acalentam ora alertam sobre a práxis acadêmica estruturante. A que nos acalenta:

No paradigma emergente, o caráter autobiográfico e autorreferenciável da ciência é plenamente assumido. A ciência moderna legou-nos um conhecimento funcional do mundo que alargou extraordinariamente as nossas perspectivas de sobrevivência [...] Para isso é necessária outra forma de conhecimento, um conhecimento compreensivo e íntimo que não nos separe e antes nos una pessoalmente ao que estudamos. (SANTOS, 2003, p. 85)

E a que nos alerta: 
A arte de andar com pessoas reside essencialmente na habilidade (que pressupõe um longo treino) de admitir, ingerir uma refeição em cujo preparo não temos confiança. Desde que cheguemos à mesa com uma fome de lobo, tudo corre facilmente ("a pior companhia te faz sentir -", como diz Mefistófeles); mas esta fome de lobo, não a temos quando dela precisamos! $\mathrm{Ah}$, como os semelhantes são difíceis de digerir!

Também nós andamos com "pessoas", também nos vestimos modestamente a roupa com a qual (como a qual) nos conhecem, nos estimam, nos procuram, e assim comparecemos em sociedade, isto é, entre pessoas disfarçadas que não querem ser tidas como tais; também nós fazemos como todas as máscaras prudentes, desembaraçando-nos polidamente de toda curiosidade de que não diga respeito a nossa "roupa". (NieTZsche, 2009, p. 266-267)

\section{HOMO ACADEMICUS: IDENTITY CRISIS AND SCIENTIFIC PRACTICE}

\section{AbStRact}

This study aims to argue on the identity of homo academicus, that is, the intellectual who has established himself within the university campus, with shared habitus and doxicological attitudes (Bourdieu, 2007; 2009; 2011). As regards the identification etiquettes, Bauman (2007) categorizes the intellectual for the scientific practices, situated by historical relations. In the convergence between space, values, and performatives, a path is laid out. From it, the logocentric practice eventually turned into dogma due to the permanence of doxicological practices of the Age of Enlightment emerges.

KEY WORDS: identity, logos, dogma, doxa.

\section{NOTAS}

1 Parte deste estudo foi apresentada no III Simpósio Nacional Discurso Identidade e Sociedade - III SIDIS, IEL, Unicamp, de 14 a 16 de fevereiro de 2012.

2 As citações referentes à obra de Zygmunt Bauman, edição francesa, 2007, La décadense des intellectuels - des législaterus aux interprètes, são traduções livres da autora.

3 Para destacar, colocamos os espaços em negrito e os habitantes em itálico. 
4 Tradução livre a partir da edição francesa de 2007. Texto original: "L'oppositin entre modernité et postmodernité a été employée ici au service de la théorization des trois derniers siècles de l'históire de l'Europe occidentale du point de vue de la praxis intellectuelle. C'est cette pratique qui peut être moderne ou postmoderne; la domination de l'un ou l'autre des deux modes distingue la modernité et la postmodernité en tant que périodes de l'histoire intelectuelle."

5 Tradução livre da edição francesa, 2007. Texto original: “[...] La stratégie postmoderne n'implique pás l'élimination de la stratégie moderne; au contraire, elle ne peut se concevoir sans la poursuite de cette dernière."

6 Tradução livre da edição francesa. Texto original: "Il consiste à traduire les idées nées à l'intérieur d'une tradition donnée afin qu'elles puissent être comprises dans un système de connaissance basé sur une autre tradition. Il ne s'agit plus de chercher à trouver le meilleur ordre social possible, mais de faciliter la communication entre des parties autonomes (et souveraine)."

7 Ver Bauman, 2007, Capítulo 1, "Paul Radin ou une étiologie des intellectuels", p. 13-50.

8 Por exemplo, áreas do saber: exatas e humanas; e suas subáreas com suas várias disciplinas.

9 Tradução do texto original: “[...] était plutôt censée créer son propre référent en soulevant des questions, en mobilisant les dévouements, en suscitant des autodéfinitions, [...] au sein d'une autorité collective politique, morale et esthétique exercée par des hommes de savoir."

10 Itálicos são acrescidos a cada tomada de sentido dicionarizado.

11 Tradução livre do texto original: "[la doxa] designe l'ensemble des croyances, associées à l'ordre des choses propre à un univers social donné, que s'imposent, de manière préréflexive et donc indiscutée, commme evidentes et inévitables."

12 Tradução livre do texto original: "le pouvoir symbolique ne désigne donc pas une forme particulière de domination mais La force que possède toute domination en mesure de se faire reconnaître, d'obtenir la reconnaissance; d'est-à-dire de se faire méconnaître dans sa vérité de pouvoir, de violence arbitraire."

13 Tradução livre do texto original: "La vision moderne du monde est typiquement celle d'une totalité relativement ordonnée; la présence d'un motif de distribution inégale des probabilités permet une forme d'explication dés événements qui, $[. .$.$] constitue à la foi un outil de prédiction et de$ maîtrise." 
14 Tradução livre do texto original: "L'ordre ne précède pas les pratiques et ne peut donc servir à mesurer leur validité."

\section{REFERÊNCIAS}

Aulete, Caldas. Dicionário Contemporâneo da Língua Portuguesa, v. II. Rio de Janeiro: Delta, 1964.

Austin, J. L. How to do Things with Words. Cambridge, Massachusetts: Harvard University Press, 1962. (Edição brasileira: Quando dizer é fazer - palavras e ação. Traduzido por Danilo Marcondes de Souza Filho. Porto Alegre: Artes Médicas, 1990).

Bauman, Sygmunt. La décadense des intellectuels - des législateurs aux interprètes. Traduction de l'anglais, Manuel Tricoteaux. Paris: Éditions Jacqueline Chambon, 2007.

Bourdieu, Pierre. O poder simbólico. 11. ed. Traduzido por Fernandoi Tomaz. Rio de Janeiro: Bertrand Brasil, 2007. (Edição francesa: Language et pouvoir symbolique. Paris: Points Eddais, 2001).

Bourdieu, Pierre. O senso prático. Traduzido por Maria Ferreira. PetrópolisRJ: Vozes, 2009. (Edição francesa: Le sens pratique. Paris Minuit, 1980. (Coll. Le sens commun)).

Bourdieu, Pierre. Homo Academicus. Traduzido por Ione Ribeiro Valle e Nilton Valle. Santa Catarina: Ed. UFSC, 2011. (Coll. Le Sens Commun). (Edição francesa: Homo Academicus. Paris, Éditions de Minuit, 1984).

Bourdieu, Pierre; Wacquant, L. J. D. Réponses. Pour une Anthropologies Réflexive. Paris: Éd. Du Euil, 1992.

Chevallier, Stéphane; Chauviré, Christiane. Dictionnaire Bourdieu. Paris: Ellipses, 2010.

Clark, B. Faculty Organization and Authority. In: Lunsford, T. F. (ed.). The Study of Academic Administration. Colorado: Western Interstate Commission for Higher Education, 1963.

DerridA, Jacques. Gramatologia. Traduzido por Miriam Chnaiderman e Renato Janine Ribeiro. 2. ed. São Paulo: Perspectiva, 1999.

Ferreira, Dina M. M. Da ciência do conhecimento e do conhecimento à prática social. In: Cilento, Angela Z. et al. Coleção, licenciaturas em debate: ciência, ensino e aprendizagem, v. 2, São Paulo: Plêiade, 2009. p. 191-200. 
FerReira, Dina M. M. Exclusão do saber: do pesquisado ao conhecimento. Revista Intercâmbio, v. XVII, p. 120-130, 2010.

Gouldner, A. W. Cosmopolitan and Locals; towards an Analysis of Latent Social Rules. Administrative Science, v. 2, p. 281-307, 1957.

Gustad, J. W. Community Consensus and Conflict. The Educational Record, v. $47,1966$.

Habermas, J. Reflections on the Linguistic Foundations of Sociology. In: . On the Pragmatics of Social. Interaction. Preliminary Studies in the Theory of Communicative Action. Traduzido por Barbara Fultner. Cambridge, Mass.: MIT Press, 2001. p. 1-103.

Isidro Pereira, S. J. Dicionário Grego-Português e Português-Grego. 5. ed. Porto: Edições Livraria Apostolado da Imprensa, 1976.

Nascentes, Antenor. Dicionário Etimológico da Língua Portuguesa, v. 1. Rio de Janeiro: Francisco Alves, Machado, J. Leite, Briguiet, Indústria do Livro, 1932 .

Nietzsche, Friederick. A gaia ciência. Traduzido por Paulo César de Souza. São Paulo: Companhia das Letras, 2009.

Rajagopalan, Kanavillil. Por uma linguística crítica: linguagem, identidade e a questão ética. São Paulo: Parábola, 2003.

Santos, Boaventura de S. Um discurso sobre as ciências. São Paulo: Cortez, 2003.

Wittgenstein, L. Investigações filosóficas. Traduzido por José Carlos Bruini. São Paulo: Nova Cultural, 1989. (Coleção Os Pensadores). 